\title{
In-hospital practice: an overview of the new guidelines for cardiopulmonary resuscitation
}

\author{
David CHAN, RN; BScN, MN (Acute Care), Nurse Specialist (ICU), Prince of Wales Hospital, Hong Kong.
}

Key words: advanced life support basic life support cardiopulmonary resuscitation guidelines in-hospital

E-mail: davidchan123@hotmail.com

\section{SUMMARY}

- $\quad$ In 2005 the International Liaison Committee on Resuscitation, the American Heart Association and the European Resuscitation Council revised and updated their cardiopulmonary resuscitation (CPR) guidelines.

- $\quad$ The in-hospital aspects of CPR practice are discussed in this article.

- $\quad$ The new guidelines emphasise the provision of high quality CPR and basic life support (BLS). That is, the performance of external cardiac compression with the following characteristics: continuous, uninterrupted, push hard, push fast, complete chest recoil, and equal time for compression and release.

- $\quad$ The effectiveness of advanced cardiac life support (ACLS) will depend on the provision of a high quality CPR. All interventions should be given on the condition that basic CPR is uninterrupted.

- $\quad$ Post-resuscitation management emphasises the institution of cardiovascular support, therapeutic hypothermia, blood glucose control, and the avoidance of routine use of hyperventilation.

\section{INTRODUCTION}

The International Liaison Committee on Resuscitation (ILCOR), the American Heart Association (AHA) and the European Resuscitation Council (ERC) have revised and updated their CPR guidelines following the 2005 International Consensus Conference on Cardiopulmonary Resuscitation and Emergency Cardiovascular Care Science (AHA, 2005; ERC, 2005; ILCOR, 2005). International resuscitation experts evaluated three years' of evidence related to CPR. The review was carried out critically on the sequence and priorities of the steps of CPR to identify those factors with the greatest potential impact on survival.

In the 2005 guidelines, based on the review of current evidence, there is an increased emphasis on ensuring that all rescuers deliver high quality CPR. In summary, rescuers should:
- $\quad$ provide an adequate number and depth of external cardiac compressions (ECC),

- allow complete chest recoil after each compression,

- $\quad$ with minimal interruption to chest compressions.

The following sections review the key points of in-hospital resuscitation, as set out in the 2005 CPR guidelines. The review will cover: basic airway management, breathing, ECC, compression: ventilation ratio, defibrillation, advanced airway management, pharmacology, ACLS, and post-resuscitation management.

\section{BASIC LIFE SUPPORT}

A summary of this section is provided in Table 1.

\section{Airway}

There is no change in the basic technique of airway management for in-hospital practice. The head-tilt chin-lift manoeuvre should be used to open the patient's airway in adults, children (aged 1 - 14 years) and infants. For patients with suspected trauma, the jaw thrust manoeuvre should be used to open the airway.

\section{Breathing}

To check for the presence of breathing, no more than 10 seconds should be used for confirmation in adults, children and infants.

For a patient who is not breathing:

- $\quad$ two rescue breaths should be given initially, at 1 second per breath, to ensure a patent airway and to re-expand the collapsed lungs. This applies to all victims, including adults, children and infants;

- $\quad$ for subsequent breaths:

adults: 10-12 breaths per minute (bpm), at 5-6 seconds per breath,

children and infants with an unprotected airway: 12-20 bpm, at 5-6 seconds per breath.

children and infants whose airway is protected should be given $8-10 \mathrm{bpm}$, at 6-8 seconds per breath. 


\section{* In-hospital practice: an overview of the new guidelines for cardiopulmonary resuscitation *}

The 2005 guidelines state that the patient's pulmonary blood flow is largely reduced during CPR, so too much ventilation is not required at this stage. The assumption is that too many, and too large, breaths will increase intrathoracic pressure, which will reduce venous return, which in turn reduces the cardiac output. Research studies have shown that over ventilating people during CPR is associated with a reduced survival rate. Therefore, when performing $C P R$, the rescue breaths should only produce a visible chest rise; too many, and too large, breaths should be avoided. There is also evidence that many first responders are not competent in delivering rescue breaths and there is potential for some of the inspired volume to be delivered into the stomach. This increases the potential for excess gastric inflation, which may result in the patient vomiting and aspirating.

\section{Checking the pulse}

When checking the pulse, no more than 10 seconds should be taken.

- $\quad$ For adults and children, the carotid pulse should be checked first.

- $\quad$ For infants, the brachial or femoral pulse should be checked.

The ERC guidelines state that pulse checking should be limited to persons who have been trained and assessed as being competent in the procedure. Also, if the rescuer is not trained in the procedure, the two initial rescue breaths should be omitted, and thirty cardiac compressions should be given immediately after cardiac arrest is established.

\section{External cardiac compression}

The 2005 guidelines recommend that rescuers should perform high quality CPR. This means that ECC should be hard and fast - at 100 compressions per minute - in a continuous and uninterrupted manner. Complete chest recoil should be allowed, and the time taken for compression and release should be equal.

\section{To determine the correct ECC site:}

- $\quad$ adults and children: rescuers should place their hands on the centre of the chest, mid-point between two nipples (as opposed to the previous rib margin method); infants: the correct position is just below the nipple line.

Two hands should be used to perform chest compressions on an adult. For children aged 1-14 years either one or both hands should be used according to the child's body size. For infants, two fingers should be used for one rescuer, and two thumbs encircling the chest to give a thoracic squeeze should be used for two rescuers.

\section{ECC depth}

- $\quad$ Adults: the chest should be compressed downwards between 1.5-2 inches (38-50 mm).

- $\quad$ Children and infants: the chest should be compressed by a third to half of the whole body thickness, according to body size.
The 2005 guidelines point out that previously there were too many interruptions and pauses during CPR, which had the effect of reducing perfusion to the brain, heart and other vital organs. The new guidelines state that continuous and uninterrupted CPR increases mean aortic blood pressure, which increases perfusion to the brain, heart, and other organs. Throughout the whole episode of CPR interruption of ECC should be avoided. If it must be interrupted, the time of interruption should be as short as possible, for example, a brief interruption to intubate.

\section{Compression: ventilation ratio}

Before intubation

- $\quad$ Adults: the compression-ventilation ratio (CV ratio) should be 30:2 (for five cycles or two minutes), for both single person rescue and two person rescue.

Children and infants: the CV ratio should also be 30:2 (for five cycles or two minutes) for one rescuer but it should be 15:2 (for eight cycles or two minutes) for two rescuers.

\section{After intubation}

- $\quad$ For adults, children and infants, no cycling of compression and ventilation is necessary.

- $\quad$ ECC and ventilation should be carried out independently.

- $\quad$ ECC should be carried out continuously at a rate of 100 compressions per minute.

- Ventilation (bagging) should be performed at a regular rate of 8-10 breaths per minute (that is, one breath every 6-8 seconds).

To avoid fatigue of the person performing compressions, the 2005 guidelines suggest that the person performing compressions should be changed every two minutes. The time taken to swap compressors should not exceed five seconds.

\section{ADVANCED LIFE SUPPORT}

\section{Defibrillation}

When a patient has collapsed and is suspected of having a cardiac arrest, previous guidelines recommended that three consecutive shocks should be given. The 2005 guidelines recommend the following:

- $\quad$ The use of a single high voltage shock (360 joules) for monophasic defibrillation.

- $\quad$ Or 120-200 joules for biphasic defibrillation (or as recommended by the manufacturer).

Defibrillation can eliminate up to $90 \%$ of ventricular fibrillation (VF) episodes. If defibrillation is unsuccessful, it is usually due to the fact that the myocardium is lacking oxygen. Therefore, a two minute period of CPR can restore oxygen to the myocardium.

- $\quad$ Subsequent shocks should be at the same level for monophasic defibrillators (360 joules) and should be either at the same level (120-200 joules) or higher when using a biphasic defibrillator. 


\section{Pulse-checking after defibrillation}

The 2005 guidelines state that after most defibrillation attempts, the patient's rhythm will usually change to either asystole or pulseless electrical activity (PEA). Even if there is a normal rhythm the heart will not be well perfused immediately after defibrillation. Furthermore, there is no evidence that continuing ECC after defibrillation will trigger further episodes of VF. Thus, defibrillation should be followed by immediate CPR to ensure adequate perfusion to the heart before pulse checking. The defibrillation cycle should be:

-

defibrillation > two minutes CPR > pulse checking, and repeat the cycles if there is still no rhythm change or no pulse.

\section{Advanced airway management}

The 2005 guidelines emphasise that basic CPR is the most effective resuscitation technique. Provided that CPR is not interrupted, health care professionals should use their training and experience to select the most appropriate type of advanced airway device, for example an endotracheal tube, laryngeal mask airway, or combitube. If airway insertion is performed by an inexperienced person the incidence of tube misplacement is likely to be high.

Confirmation of airway placement is needed immediately following airway placement, during transport, and after moving the patient. To reduce the incidence of airway misplacement, in addition to using a stethoscope, it is recommended that other devices are used to help confirm the correct position, for example a carbon dioxide sensor. After insertion of an advanced airway, synchronisation of chest compression with ventilation is not needed. The ERC (2005) guideline is similar, unless there is a significant air leakage.

\section{Pharmacology}

The medications recommended in the 2005 guidelines are similar to those used in previous guidelines, with only minor changes. The current recommendations are that:

\begin{tabular}{|c|c|c|c|c|}
\hline \multicolumn{2}{|l|}{ Manoeuvre } & Adult & $\begin{array}{l}\text { Child } \\
\text { (1-14 years) }\end{array}$ & $\begin{array}{l}\text { Infant } \\
\text { (under } 1 \text { year) }\end{array}$ \\
\hline \multicolumn{2}{|l|}{ Airway } & \multicolumn{3}{|c|}{$\begin{array}{l}\text { - Use head tilt-chin lift } \\
\text { - Use jaw thrust (for suspected trauma) }\end{array}$} \\
\hline \multirow[t]{2}{*}{ Breathing } & Initial breaths & \multicolumn{3}{|c|}{ Give two breaths at 1 second per breath } \\
\hline & $\begin{array}{l}\text { Subsequent } \\
\text { breaths }\end{array}$ & $\begin{array}{l}\text { Breathing only: 10-12 } \\
\text { breaths/minute (5-6 } \\
\text { seconds/breath) } \\
\text { - Breathing with ECC: } \\
\text { 8-10 breaths/minute } \\
\text { (6-8 seconds/breath) }\end{array}$ & \multicolumn{2}{|c|}{$\begin{array}{l}\text { - Breathing only: } 12-20 \text { breaths/minute } \\
\text { (3-5 seconds/breath) } \\
\text { - Breathing with ECC: } 8-10 \text { breaths/minute } \\
\text { (6-8 seconds/breath) }\end{array}$} \\
\hline \multirow{5}{*}{$\begin{array}{ll}\text { Compression } \\
- & \text { Uninterrupted } \\
- & \text { Push hard, push fast } \\
- & \text { Recoil completely } \\
\text { - } & \text { Equal time for } \\
& \text { compression and } \\
& \text { release }\end{array}$} & Check pulse & \multicolumn{2}{|c|}{ Check carotid pulse for no more than 10 seconds } & $\begin{array}{l}\text { Check brachial or } \\
\text { femoral pulse for no } \\
\text { more than } 10 \text { seconds }\end{array}$ \\
\hline & ECC Site & \multicolumn{2}{|l|}{ Mid-nipple line } & Just below nipple line \\
\hline & ECC Method & Use two hands & $\begin{array}{l}\text { Use one or two hands } \\
\text { according to body size }\end{array}$ & 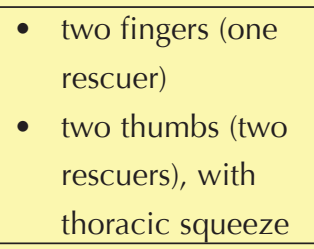 \\
\hline & ECC Depth & $1.5-2$ inches $(38-50 \mathrm{~mm})$ & \multicolumn{2}{|l|}{$1 / 3-1 / 2$ chest depth } \\
\hline & ECC Rate & \multicolumn{3}{|l|}{100 breaths/minute } \\
\hline \multirow[t]{2}{*}{$\begin{array}{l}\text { Compression: ventilation } \\
\text { ratio }\end{array}$} & $\begin{array}{l}\text { Before } \\
\text { intubation }\end{array}$ & $\begin{array}{l}\text { - One-rescuer at 30:2 } \\
\text { for } 5 \text { cycles ( } 2 \text { minutes) } \\
\text { - } \text { Two-rescuer at } 30: 2 \\
\text { for } 5 \text { cycles ( } 2 \text { minutes) }\end{array}$ & \multicolumn{2}{|c|}{$\begin{array}{l}\text { - One-rescuer at 30:2 for } 5 \text { cycles (2 minutes) } \\
\text { - Two-rescuers at 15:2 for } 8 \text { cycles (2 minutes) }\end{array}$} \\
\hline & After intubation & \multicolumn{3}{|c|}{$\begin{array}{l}\text { - } \\
\text { - } \quad \text { EC cycles are needed. } 100 \text { breaths/minute continuously } \\
\text { Bagging at 8-10 breaths/minute (bag once every 6-8 seconds) }\end{array}$} \\
\hline
\end{tabular}


medications should be prepared in advance,

- drug administration should not interrupt ECC,

- drug administration should be preferably via the intravenous (IV) or intraosseous routes [rather than via an endotracheal tube (ETT), because the drug absorption into the blood is very low via ETT administration, and the drug effect is therefore weak].

Vasopressors (for example adrenaline and vasopressin) should be given after the first one or two shocks. Studies have demonstrated that there is no significant difference in effect between adrenaline and vasopressin. Both drugs can be used for treating ventricular tachycardia (VT) and VF, PEA and asystole.

Anti-arrhythmic drugs (for example amiodarone and lignocaine) should be given after the second or third shock. The new guidelines recommend the use of amiodarone in preference to lignocaine, because there is better evidence of its effect.

When treating bradycardia or heart block, atropine is still the drug of choice. However, there is the minor change in the recommended dose (see below). When treating supraventricular tachycardia (SVT), the preferred drug is still adenosine. (See Table 2 for commonly used drugs during CPR.)

\section{ADVANCED CARDIAC LIFE SUPPORT}

The 2005 guidelines emphasise that the effectiveness of ACLS is based upon the provision of a high quality CPR, which should be continuous and uninterrupted. Furthermore, the implementation of all other interventions (such as drug administration, endotracheal intubation and defibrillation) should be undertaken on the condition that CPR is not being interrupted.

The following section provides a summary of the various ACLS algorithms.

\section{Pulseless ventricular tachycardia and ventricular fibrillation}

The algorithm for pulseless VT and VF is largely unchanged. Their management should include:

- $\quad$ high quality CPR;

- $\quad$ early defibrillation;

- $\quad$ use of vasopressors (adrenaline or vasopressin) after the first or second shock,

- $\quad$ use of anti-arrhythmic drugs (amiodarone or lignocaine). Magnesium sulphate is used for treating Torsade de Pointes VT;

- Identify and manage reversible problems, including the $6 \mathrm{H}$ and $6 \mathrm{~T}$ problems.

o $6 \mathrm{H}$ refers to hypoxia, hypovolaemia, hydrogen ions (acidosis), hyper- and hypokalaemia, hypothermia, and hypoglycaemia,

o 6T refers to toxins (drug overdose), tension pneumothorax, tamponade - cardiac, thrombosis - cardiac (acute myocardial infarction), thrombosispulmonary (pulmonary embolism), and trauma.

Pulseless electrical activity and asystole

The treatment for both PEA and asystole is the same. It includes:

- $\quad$ high quality CPR;

- $\quad$ use of vasopressors; use of atropine;

\begin{tabular}{|c|c|c|}
\hline Drug & Indications & Dosage \\
\hline Adrenaline & $\begin{array}{ll}\text { - } & \text { Pulseless VT, VF } \\
\text { - } & \text { PEA, asystole } \\
\end{array}$ & - 1 mg IV every 3-5 minutes \\
\hline Vasopressin & $\begin{array}{l}\text { - } \text { Pulseless VT, VF } \\
\text { - } \quad \text { PEA, asystole } \\
\end{array}$ & - 40 units IV (single dose) \\
\hline \multirow[t]{2}{*}{ Amiodarone } & - Pulseless VT, VF & $\begin{array}{l}\text { - } 300 \mathrm{mg} \text { IV, followed by } 150 \mathrm{mg} \text { (maximum dose } 2.2 \mathrm{~g} \text { ) } \\
\text { - Infusion: } 1 \mathrm{mg} / \mathrm{minute} \text { for } 6 \text { hours, then } 0.5 \mathrm{mg} / \text { minute for } 18 \\
\text { hours (maximum dose } 2.2 \mathrm{~g} \text { per day) }\end{array}$ \\
\hline & $\begin{array}{l}\text { - } \quad \text { Pulsed VT } \\
\text { - } \text { Other forms of tachycardia }\end{array}$ & $\begin{array}{l}\text { - } 150 \mathrm{mg} \text { IV, repeating as needed (maximum dose } 2.2 \mathrm{~g} \text { per day) } \\
\text { - Infusion: } 1 \mathrm{mg} / \mathrm{minute} \text { for } 6 \text { hours, then } 0.5 \mathrm{mg} / \mathrm{minute} \text { for } 18 \\
\text { hours (maximum dose } 2.2 \mathrm{~g} \text { per day) }\end{array}$ \\
\hline Lignocaine & $\begin{array}{ll}\text { - } & \text { Pulseless VT, VF } \\
\text { - } & \text { Pulsed VT, other forms of } \\
& \text { tachycardia } \\
\end{array}$ & $\begin{array}{l}\text { - } 1-1.5 \mathrm{mg} / \mathrm{kg} \text {, then } 0.5-0.75 \mathrm{mg} / \mathrm{kg} \text { (max not to exceed } 3 \text { doses } \\
\text { or } 3 \mathrm{mg} / \mathrm{kg} \text { ) } \\
\text { - Infusion: } 1-4 \mathrm{mg} / \text { minute }\end{array}$ \\
\hline $\mathrm{MgSO} 4$ & - Torsade de pointes VT & - 1-2 g IV single dose \\
\hline Atropine & $\begin{array}{l}\text { - } \text { Asystole, PEA } \\
\text { - } \text { Bradycardias } \\
\text { - } \text { Heart Blocks }\end{array}$ & $\begin{array}{l}\text { - } 1 \mathrm{mg} \text { IV every 3-5 minutes (maximum dose not to exceed } 3 \text { doses } \\
\text { or } 3 \mathrm{mg} \text { ) } \\
\text { - } 0.5 \mathrm{mg} \text { IV every 3-5 minutes (maximum dose not to exceed } \\
3 \mathrm{mg} \text { ) }\end{array}$ \\
\hline Adenosine & $\begin{array}{l}\text { - Paroxysmal supraventricular } \\
\text { tachycardia }\end{array}$ & - $6 \mathrm{mg}$ IV, then $2 \mathrm{mg}$, then $12 \mathrm{mg}$ \\
\hline
\end{tabular}

Table 2: Commonly used drugs during CPR 
identification and management of reversible problems.

When giving IV atropine the correct dose is:

- $\quad 1 \mathrm{mg}$ IV every 3-5 minutes, up to a maximum of $3 \mathrm{mg}$ (AHA, 2005),

- $\quad$ however, it should be noted that the ERC (2005) guideline is different: it suggests a single dose $3 \mathrm{mg}$ IV bolus.

Transcutaneous pacing (TCP) is no longer recommended for the management of asystole.

\section{Bradycardia and heart blocks}

Management for bradycardia and heart blocks is:

- $\quad$ oxygen, monitor and IV set up;

- $\quad$ for patients with bradycardia and low grade heart block, try atropine first $0.5 \mathrm{mg}$ IV (up to a maximum dose of 3 $\mathrm{mg}$ );

- $\quad$ for high grade heart block, try using TCP. If it is ineffective or the patient develops hypotension, proceed using atropine or inotropic infusion (for example, adrenaline or dopamine);

- $\quad$ when the patient is stable, try changing to transvenous pacing, and identify the cause.

Unstable tachycardia

Unstable tachycardia refers to a tachycardia with a heart rate of greater than 150 beats per minute with an associated drop in blood pressure. These tachycardias may be:

- atrial fibrillation (AF),

- atrial flutter,

- SVT,

- $\quad$ or pulsed VT.

Management should include:

- $\quad$ oxygen, monitor and IV set up;

- if the patient is conscious, give sedatives;

- $\quad$ try cardioversion;

- for atrial flutter and paroxysmal supraventricular tachycardia (PSVT), the defibrillation voltage should be commenced at 50 joules, and for other forms of unstable tachycardia, defibrillation voltage should be commenced at 100 joules.

\section{Stable tachycardia}

Stable tachycardia refers to tachycardias with a heart rate of greater than 150 beats per minute with a normal blood pressure. The 2005 guidelines use a different approach in the classification of stable tachycardias, which are:

$$
\begin{array}{ll}
\text { - } & \mathrm{AF}, \\
\text { - } & \text { atrial flutter, }
\end{array}
$$

$\begin{array}{ll}- & \text { SVT } \\ - & \text { or pulsed VT. }\end{array}$

Management should include:

- $\quad$ perform a 12-lead ECG first to differentiate whether the QRS is a narrow complex or a wide complex (QRS interval less than 0.12 second is narrow complex, QRS interval more than 0.12 second is wide complex);

- $\quad$ identify whether the rhythm is regular or irregular;

- $\quad$ Then treat accordingly.

Narrow complex and regular rhythm

The patient may have developed:

- $\quad$ PSVT,

- $\quad$ Atrial flutter,

- $\quad \mathrm{AF}$,

- $\quad$ or junctional tachycardia.

Management should include:

- $\quad$ vagal manoeuvre, for example carotid massage;

- $\quad$ IV adenosine to slow down the heart rate. If the heart rate can be slowed down, the rhythm should be PSVT. If there is no response, the rhythm should be either atrial flutter, atrial tachycardia or junctional tachycardia; then try calcium channel blockers (for example diltiazem) or a beta-blocker (for example metoprolol).

Narrow complex and irregular rhythm

The patient may have developed:

- $\mathrm{AF}$,

- atrial flutter

- $\quad$ or multifocal tachycardia (MAT).

Management should include:

- $\quad$ calcium channel blockers (for example diltiazem);

- $\quad$ or a beta-blocker (for example metoprolol).

Wide complex and regular rhythm

The patient may have developed pulsed VT.

Management should include:

- amiodarone;

- $\quad$ cardioversion if needed;

- $\quad$ if the patient develops PSVT with aberrant conduction, try adenosine.

Wide complex and irregular rhythm

- If the patient develops AF with aberrant conduction, try calcium channel blockers (for example diltiazem) or beta-blocker (for example metoprolol). 
If the patient develops AF with Wolf-Parkinson-White (WPW) syndrome, try amiodarone and avoid using atrioventricular node blockers (for example. adenosine, digoxin, diltiazem, verapamil) to prevent triggering VF.

- If the patient develops Torsade de pointes VT, try magnesium sulphate. And if the patient develops refractory polymorphic VT, consult a cardiologist.

\section{POST RESUSCITATION MANAGEMENT}

Post-resuscitation management now emphasises the importance of supporting the cardiovascular system and other vital organ functions. In particular, the 2005 guidelines recommend:

- $\quad$ supporting the patient's blood pressure;

- $\quad$ reducing the patient's body temperature (using therapeutic hypothermia by lowering the body temperature to 32-34 degrees Celsius for 12-24 hours); - $\quad$ controlling the patient's blood glucose level to prevent hyperglycaemia;

- $\quad$ and avoiding routine hyperventilation.

\section{CONCLUSIONS}

According to the 2005 CPR guidelines, high quality CPR is essential to help achieve a better resuscitation outcome. Following the release of the new guidelines in December 2005, hospitals in Hong Kong have started incorporating them into CPR training and hospital resuscitation practices. With respect to the nurse's role, ICU nurses have a responsibility to learn and master the new CPR concepts and skills. CPR knowledge and skills require regular updating and practising, so that the quality of care of critically ill patients is maintained at a high standard.

\section{REFERENCES}

American Heart Association (2005). American Heart Association guidelines for cardiopulmonary resuscitation and emergency cardiac care. Circulation 112 (24 Suppl. 1), IV 1-203.

International Liaison Committee on Resuscitation (2005). International consensus on CPR and ECC science with treatment recommendations. Circulation 112 (22 Suppl. 1).

European Resuscitation Council (2005). ERC Guidelines for Resuscitation, Resuscitation 67 (Suppl. 1), S1-S190. 